\title{
ANATOMICAL VARIATIONS OF THE SUPERIOR CEREBELLAR ARTERY: A CADAVERIC STUDY AT THE UNIVERSITY TEACHING HOSPITALS, LUSAKA, ZAMBIA
}

\author{
Mickey Banda' ${ }^{1}$ Caswell Hachabizwa ${ }^{1}$, Joseph Hainza ${ }^{1}$, Sikhanyiso Mutemwa ${ }^{1}$, Krikor Erzingastian² \\ ${ }^{1}$ Department of Anatomy, School of Medicine, University of Zambia, Lusaka, Zambia \\ ${ }^{2}$ Department of Surgery and Anatomy, School of Medicine, University of Zambia, Lusaka, Zambia \\ Correspondence to Mr Mickey Banda. Email: mickeybanda2003@yahoo.com
}

\begin{abstract}
The superior cerebellar artery usually arises from the terminal end of the basilar artery. It may also originate from the posterior cerebral artery and or from a common trunk with the posterior cerebral artery. The anatomical variations of superior cerebellar artery show ethnic differences, but there are few reports on African populations in particular none from Zambia. Variations of the superior cerebellar artery might cause compression symptoms of cranial nerves III, IV and V. Furthermore, the presence of such variations has been considered to be a factor in the aetiology of aneurysms and thrombus formation leading to cerebellar infarcts. The objectives of the study were to explore anatomical variations on the origin of the superior cerebellar artery; to measure the outer diameter at its origin and the length of superior cerebellar artery to its first bifurcation; to establish the presence of duplication, triplication, hypoplasia, agenesis, fenestration and any other anomalies that were detectable. This was a descriptive cross-sectional study in which 46 post-mortem human cadaveric brains were systematically sampled. A total of 113 superior cerebellar arteries were identified in 42 male and four female cadavers of age ranging between 18 and 65 years (mean 34.05 $\pm 9.237 \mathrm{~mm}$ ). Superior cerebellar artery arose from the basilar artery as a single vessel in $49.5 \%$, the common trunk arose in $6.2 \%$ and posterior cerebral artery origin was seen in $5.7 \%$. Overall duplication of the superior cerebellar artery was seen in $35.5 \%$ and triplication in $5.3 \%$. Nineteen $(16.8 \%)$ of the superior cerebellar arteries were hypoplastic (less than $1 \mathrm{~mm}$ ) and ninety-four (83.2\%) were normal. The diameter of the superior cerebellar artery at its origin ranged $0.25 \mathrm{~mm}$ to $2.48 \mathrm{~mm}$ (mean $1.42 \pm 0.54 \mathrm{~mm}$ ). The length of the superior cerebellar artery to its first bifurcation ranged from $3.77 \mathrm{~mm}$ to $33.53 \mathrm{~mm}$ (mean $21.92 \pm 7.40 \mathrm{~mm}$ ). Statistically, gender had no significant association of superior cerebellar artery variations $(p>0.05)$. This knowledge will improve diagnosis and management of patients with vascular disorders of the posterior circulation. The newly identified patterns could be a contribution to the SCA classification system.
\end{abstract}

Key words: Superior cerebellar artery, duplication, triplication and hypoplasia

\section{INTRODUCTION}

The superior cerebellar artery (SCA) arises at the terminal end of the basilar artery, immediately before the formation of the posterior cerebral artery (PCA) (Standring, 2008). It may also originate from the PCA and or from a common trunk with the PCA (Ogeng'o et al., 2015; Kalaiyarasi and Chitra, 2018). A number of variations have been described in the literature which includes origin and pattern of SCA. The presence of SCA variations has been considered to be a factor in the aetiology of aneurysms and thrombus formation leading to cerebellar infarct (Padmavathi, 2014). The SCA is intimately related to oculomotor, trochlear and trigeminal nerves. Therefore, variations of the SCA can alter its relationship with cranial nerves causing compression symptoms (Zheng et al., 2012). 
Anatomical variations of the SCA show ethnic differences, but there they are scant reports on African populations (Ogeng'o et al., 2015). Knowledge on anatomical variations of the SCA will improve the diagnosis and management of posterior vascular occlusion. The Knowledge on anatomical variations of the SCA will improve the diagnosis and management of posterior vascular occlusion. Such information can be of benefit to anatomists in teaching anatomy, vascular surgeons, neurosurgeons and interventional radiologists. Furthermore, with the advent of a Catheter Laboratory at the University Teaching Hospitals detailed knowledge on cerebral vascular anomalies in a Zambian population could form an important foundation for the future development of the specialties of endovascular diagnosis and surgery.

\section{MATERIAL AND METHODS}

This was a cross-sectional descriptive study by design that was conducted at the Pathology Department, University Teaching Hospitals, Lusaka, Zambia. A total of 113 SCAs were identified in 42 male and four female cadavers of age ranging between 18 and 65 years (mean $34.05 \pm 9.237 \mathrm{~mm}$ ). A systematic sampling was employed to select cadavers.
A coronal incision was made between the two mid-ear points with the scalp being reflected, the anterior flap anteriorly and the posterior flap posteriorly. The brain was removed extradurally; the base was detached from the floor of the cranial cavity and the arachnoid mater exposed.

\section{RESULTS}

The data captured showed majority forty-two $(91.3 \%)$ were male and compared to four $(8.7 \%)$ were female cases. A total of 113 SCAs were identified in 46 cadavers of age ranging between 18 and 65 years (mean
$34.05 \pm 9.237 \mathrm{~mm})$. The SCA arose from the BA in fifty-six cases (49.6\%), overall duplication was seen in forty cases (35.5\%) and triplication was observed in six cases (5.3\%).

Table 1: Origin of the SCA and patterns of variations

\begin{tabular}{|l|l|l|l|l|l|}
\hline Pattern of SCA & Origin of the SCA & Right & Left & $\begin{array}{l}\text { No. of } \\
\text { cases }\end{array}$ & Percentage \\
\hline \multirow{3}{*}{ Single vessel } & From BA & 28 & 28 & 56 & $49.6 \%$ \\
\cline { 2 - 6 } & From PCA & 3 & 2 & 5 & $4.4 \%$ \\
\cline { 2 - 5 } & From Common trunk & 2 & 4 & 6 & $5.3 \%$ \\
\hline \multirow{3}{*}{ Duplication } & From BA & 16 & 20 & 36 & $31.9 \%$ \\
\cline { 2 - 6 } & From PCA & 2 & 0 & 2 & $1.8 \%$ \\
\hline Triplication & Common Trunk & 0 & 2 & 2 & $1.8 \%$ \\
\hline Total & From BA & 6 & 0 & 6 & $5.3 \%$ \\
\hline
\end{tabular}

The most common origin of the SCA was a single vessel which took origin from the $B A$ was observed in fifty-six cases (49.9\%). The commonest variation of the SCA was duplication from the BA which was seen in thirty-six cases (31.9\%) while triplication accounted for six cases (5.3\%). 
Anatomy Journal of Africa. 2020. Vol 9 (1): 1789 - 1796.

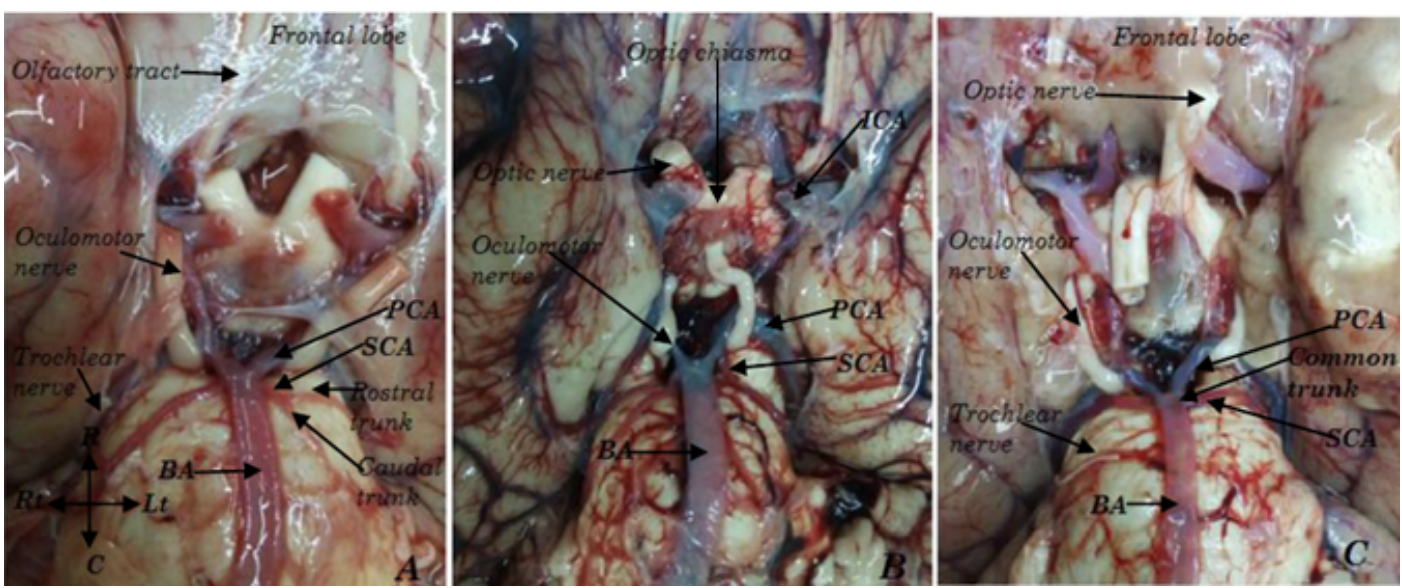

Figure 1: (A) Single vessel origin of the SCA from the BA, (B) PCA origin of the left SCA, (C) Common trunk origin of the SCA.
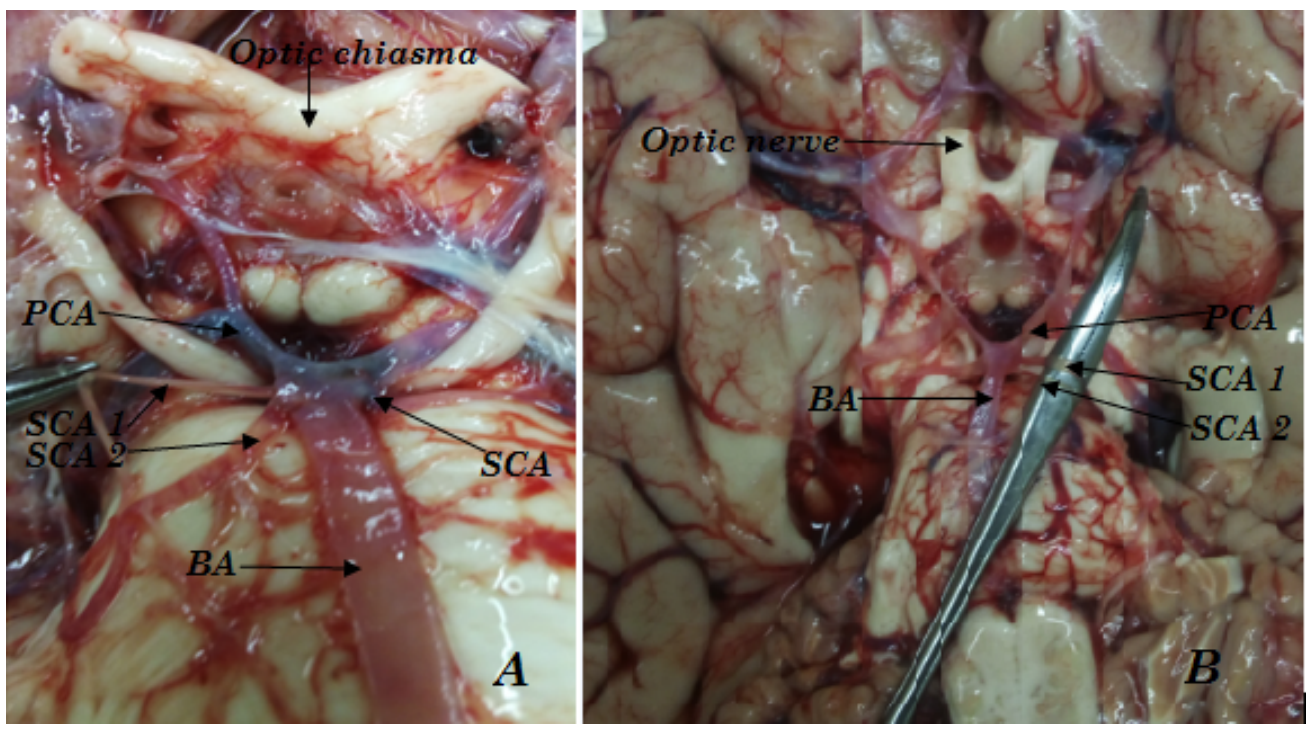

Figure 2: (A) Right duplicated SCAs, (B) Left duplicated SCAs
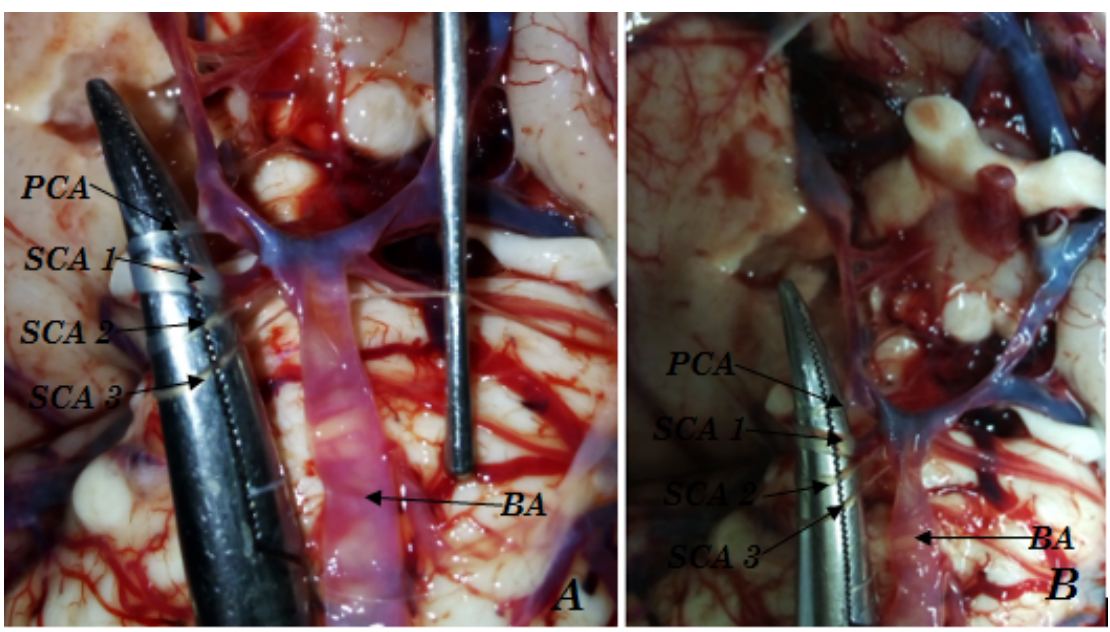

Figure 3: $(A)$ and (B) Right triplication of SCAs 

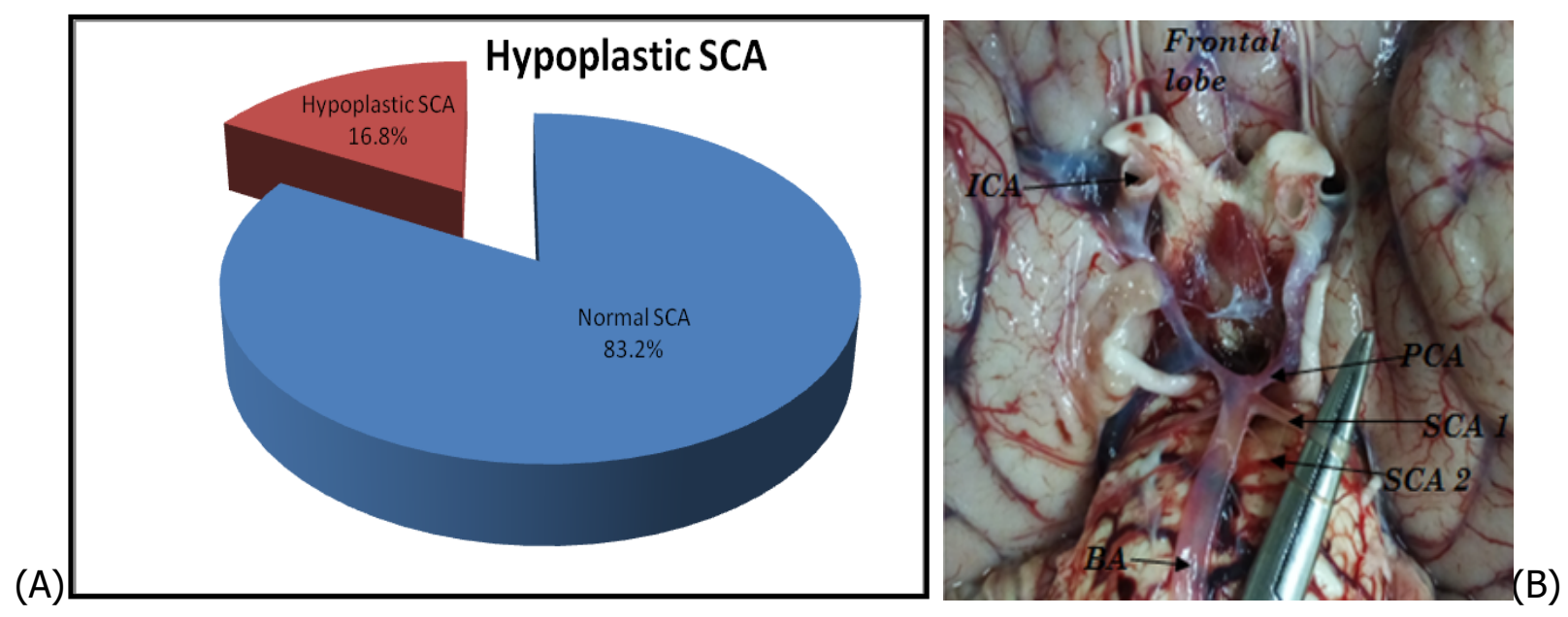

Figure 4: (A) Hypoplasia (less than 1mm) of the SCA was observed in nineteen (15.6\%) of the cases were and ninety four $(83.2 \%)$ were normal. (B) Lt second hypoplastic SCA

The length of the SCA was measured from origin to the point of its first bifurcation which ranged from $3.77 \mathrm{~mm}$ to $33.53 \mathrm{~mm}$ (mean was $21.92 \pm 7.40 \mathrm{~mm}$ ).

Table 2: Descriptive Statistics (Diameter of the SCA)

\begin{tabular}{|l|l|l|l|l|l|}
\hline Characteristics & N & Minimum & Maximum & Mean & SD \\
\hline Rt SCA 1 & 46 & 1.02 & 2.22 & 1.6152 & .40458 \\
\hline Lt SCA 1 & 46 & .39 & 2.48 & 1.5255 & .49128 \\
\hline Rt SCA 2 & 11 & .25 & 1.23 & .5745 & .27908 \\
\hline Lt SCA 2 & 4 & 1.00 & 1.56 & 1.3625 & .26487 \\
\hline Rt SCA 3 & 6 & .33 & .96 & .6700 & .25282 \\
\hline
\end{tabular}

Table 4 shows that the diameter of the SCA ranged between $0.25 \mathrm{~mm}$ to $2.48 \mathrm{~mm}$.

Table 3: Krzyzewski's Classification of SCA

\begin{tabular}{|l|l|l|l|}
\hline Type & Frequency & Percent & Cumulative Percent \\
\hline Type 1 & 28 & 60.9 & 60.9 \\
\hline Type 3a & 3 & 6.5 & 67.4 \\
\hline Type 3b & 6 & 13.0 & 80.4 \\
\hline Type 4a & 1 & 2.2 & 82.6 \\
\hline Type 4b & 2 & 4.3 & 86.9 \\
\hline Type 5b & 2 & 4.3 & 91.2 \\
\hline Unclassified & 4 & 8.7 & 100.0 \\
\hline Total & 46 & 100.0 & \\
\hline
\end{tabular}

The majority twenty eight (60.9\%) were type 1 while four cases $(8.7 \%)$ were unclassified. 

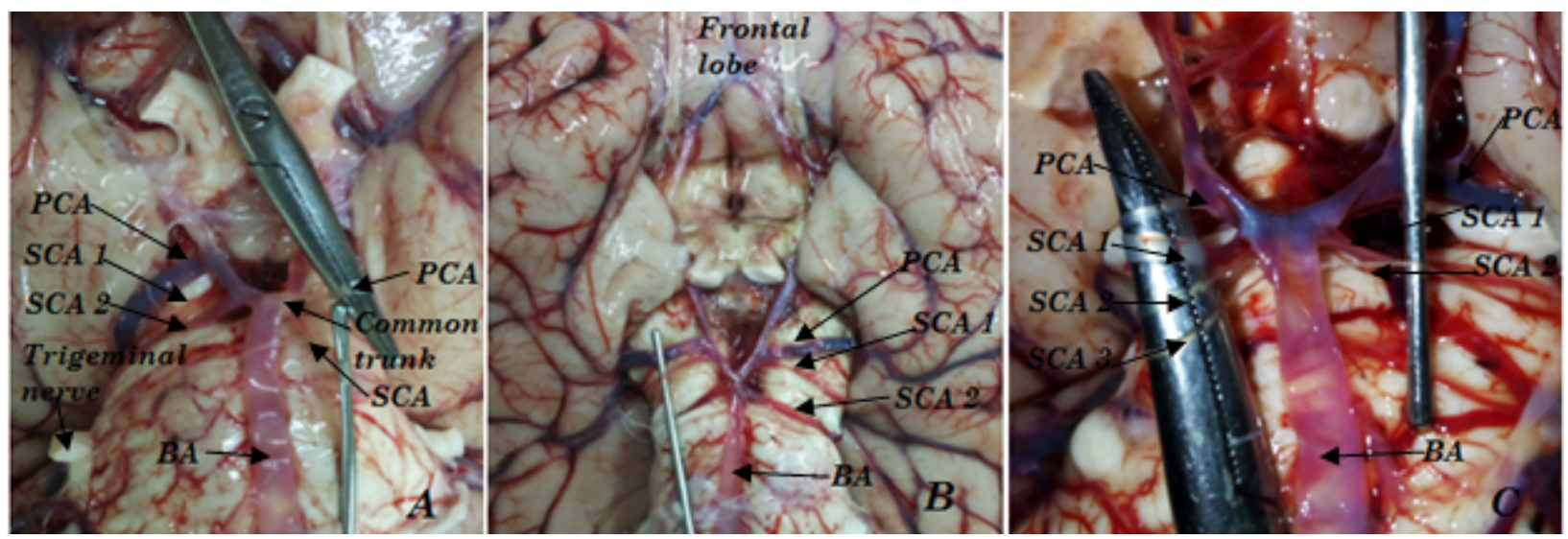

Figure 5: $(A)$ and (b): Picture (a) right SCA originating from the PCA and left duplicated SCA originating from the common trunk, and (b) bilateral origin from both the BA and PCA (black arrows pointing at the SCAs).

\begin{tabular}{|c|c|c|c|c|c|c|c|}
\hline \multirow{2}{*}{\multicolumn{3}{|c|}{ Variable }} & \multirow{2}{*}{\multicolumn{2}{|c|}{ Variations in SCA }} & \multirow[t]{3}{*}{ Total } & \multirow{2}{*}{$\begin{array}{l}\text { Fisher's } \\
\text { Exact } \\
\text { Test }\end{array}$} & \multirow{2}{*}{$\begin{array}{l}\text { P } \\
\text { value }\end{array}$} \\
\hline & & & & & & & \\
\hline \multirow{4}{*}{ Gender } & Male & Count & 26 & 16 & & \multirow{6}{*}{.637} & \multirow{6}{*}{.641} \\
\hline & & $\%$ & $56.2 \%$ & $34.8 \%$ & $91.0 \%$ & & \\
\hline & Female & Count & 2 & 2 & 4 & & \\
\hline & & $\%$ & $4.4 \%$ & $4.4 \%$ & $8.8 \%$ & & \\
\hline \multirow{2}{*}{\multicolumn{2}{|c|}{ Total }} & Count & 28 & 18 & 46 & & \\
\hline & & $\%$ & $60.9 \%$ & $39.2 \%$ & $100.0 \%$ & & \\
\hline
\end{tabular}

The abnormal patterns of the SCA were found in sixteen (34.8\%) were male and while in two (4.4\%) were female. The P-value $>0.05$ was considered not statistically significant.

\section{DISCUSSION}

In the present study it was found that the most common origin of the SCA was from the BA as a single trunk in $49.6 \%$. Previously, a number of studies have documented that the commonest origin of the SCA is a single trunk from the BA with its frequency ranging from $48.7 \%$ to $96.33 \%$. Our findings were almost similar with Nagawa et al. (2018), who reported the origin of the SCA as a single vessel in $51.3 \%$ in a black Ugandan population. However, these results were contrary to the findings of Ogeng'o et al. (2015) who reported a higher rate of single origin of the SCA from the BA with a frequency of $72.1 \%$ in a black Kenyan population.

In the current study, the SCA took origin from the PCA in $5.7 \%$ of the cases. This finding is consistency with various studies that have reported the origin of the SCA from the PCA with the frequency ranging between $2-4.8 \%$ (Aydin et al., 2011; Bala et al., 2013; Dodevski et al., 2015). Such common variations of the SCA may lead to misdiagnosis and mismanagement of diseases related to the SCA (Dagcinar et al., 2007; Kalani et al., 2013).

The SCA also took origin from the common trunk of the PCA and the SCA at a frequency of $6.2 \%$ in the present study. The current study is in agreement with other studies that reported a frequency ranging from $2.5 \%$ to $9.4 \%$. This anomaly is as a result of abnormal development during embryogenesis and fusion of primitive neural arteries. 
The overall duplication of the SCA was observed at the rate of $35.5 \%$. The current study finding is almost comparable with Ogeng'o et al. (2015) who reported duplication as the most common anomaly of the SCA with the frequency of $21.3 \%$. The duplication of the SCA is due to direct origin of branches of SCA such as the marginal artery from BA (Dagcinar et al., 2007; Kalaiyalasi \& Chitra, 2018). Therefore, the clinical significance of this anatomical variant is that the additional artery may provide alternative circulation in the case of a thromboembolism (Ogeng'o et al., 2015).
In the present study, triplication was observed in $4.9 \%$ of the cases, all were right unilateral SCAs arising from the BA. This finding is slightly lower than the reported cases of $6.1 \%$ by Nagawa et al. (2018) in a Ugandan black population. On the other hand, the present study finding is almost comparable with the study done by Gunnal et al. (2014) who reported triplication at the rate of $5.29 \%$. However, in their study they considered triplication of the SCA arising from BA, PCA and the common trunk altogether.

Table 5: Comparison on the origin of the SCA with other studies

\begin{tabular}{|c|c|c|c|c|c|c|}
\hline \multirow{2}{*}{ Studies } & \multirow{2}{*}{$\begin{array}{l}\text { No of } \\
\text { SCA } \\
\text { studied }\end{array}$} & \multicolumn{3}{|c|}{ Origin of the SCA } & \multicolumn{2}{|c|}{ Patterns } \\
\hline & & BA & PCA & $\begin{array}{l}\text { Commo } \\
\text { n trunk }\end{array}$ & $\begin{array}{l}\text { Duplicatio } \\
\text { n }\end{array}$ & Triplication \\
\hline Current study & 113 & $49.5 \%$ & $\begin{array}{l}6.2 \\
\%\end{array}$ & $7.1 \%$ & $35.5 \%$ & $5.3 \%$ \\
\hline $\begin{array}{l}\text { Kalaiyalasi \& } \\
\text { Chitra, } 2018\end{array}$ & 160 & $75.6 \%$ & $\begin{array}{l}1.9 \\
\%\end{array}$ & $3.1 \%$ & $17.5 \%$ & $1.9 \%$ \\
\hline Padmavathi, 2014 & 150 & $49.4 \%$ & & $25.3 \%$ & $23.3 \%$ & $2 \%$ \\
\hline $\begin{array}{l}\text { Krzyżewski et al. } \\
2014\end{array}$ & 388 & $76.1 \%$ & & $2 \%$ & $3.09 \%$ & None \\
\hline $\begin{array}{l}\text { Ogeng'o et al. } \\
2015\end{array}$ & 394 & $72.1 \%$ & $\begin{array}{l}2.5 \\
\%\end{array}$ & $4.0 \%$ & $21.3 \%$ & None \\
\hline
\end{tabular}

The diameter of the right SCA measured between $0.25 \mathrm{~mm}$ to $2.22 \mathrm{~mm}$ (mean $1.41 \pm 0.56 \mathrm{~mm}$ ) and left SCA was 0.33 to $2.48 \mathrm{~mm}$ (mean $1.42 \pm 0.53 \mathrm{~mm}$ ). Literature reported the diameter of the SCA ranged between hypoplastic (less than $1 \mathrm{~mm}$ ) to $2.46 \mathrm{~mm}$. In the current study, the findings are contrary to Padmavathi (2014) who reported the mean diameters of the SCA to be $2.0 \pm 0.4 \mathrm{~mm}$ on the right and $1.9 \pm 0.3 \mathrm{~mm}$ on the left side.

Comparing the diameter of the SCA on the same side, we found the diameter of the first right SCA ranged between $1.02 \mathrm{~mm}$ to $2.22 \mathrm{~mm}$ (mean $1.62 \pm 0.41 \mathrm{~mm})$, second right SCA ranged between $0.25 \mathrm{~mm}$ to $1.23 \mathrm{~mm}$ (mean $0.58 \pm 0.28 \mathrm{~mm}$ ) and the third right SCA ranged between $0.33 \mathrm{~mm}$ to $0.96 \mathrm{~mm}(0.67 \pm 0.25 \mathrm{~mm})$. Therefore, it was observed that the diameter of the second SCAs reduced progressively but this was inconclusive in the case of a third SCAs. This finding was consistent with the reports on the SCA variations that the diameter progressively reduced in multiple SCAs (Avci et al., 2001; Dodevski et al., 2015). The clinical significance of the outer diameter of the vessel is that it may influence the frequency and severity of neurovascular events. On the other hand, 
multiple SCAs may provide alternative circulation in the case of occlusion.

Concerning the length of the SCA, it was measured from origin to its first bifurcation which ranged from $3.77 \mathrm{~mm}$ to $33.53 \mathrm{~mm}$ (mean was $21.92 \pm 7.40 \mathrm{~mm}$ ). These findings were inconsistent with both Padmavathi (2014) who reported the length of the SCA ranging between $6 \mathrm{~mm}$ to $23 \mathrm{~mm}$ and, Kalaiyalasi and Chitra (2018) reported $9 \mathrm{~mm}$ to $24 \mathrm{~mm}$. Hypoplasia of the SCA was considered with outer diameter less than 1mm (Habibi et al., 2011; Padmavathi, 2014).
The current study found nineteen (16.8\%) of the SCAs were hypoplastic and ninety four (83.2\%) were normal (more than $1 \mathrm{~mm}$ ). This finding was significantly contrary to Padmavathi (2014) who reported the frequency of hypoplasia of the SCA at rate of $0.7 \%$. The majority of studies didn't report about SCA hypoplasia. This form of vascular anomaly can contribute to altered dynamics of blood flow and the development of aneurysms (Nair \& Panikar, 2015; Kalaiyalasi \& Chitra, 2018). Agenesis and fenestration were not observed in the present study.

Table 6: Comparisons of various studies on the diameter of the SCA
\begin{tabular}{|l|l|l|}
\hline Study & Right side & Left side \\
\hline Padmavathi 2014 & $2.0 \pm 0.4 \mathrm{~mm}$ & $1.9 \pm 0.3 \mathrm{~mm}$ \\
\hline Kalaiyalasi and Chitra 2018 & $1.8 \pm 0.5 \mathrm{~mm}$ & $1.6 \pm 0.4 \mathrm{~mm}$ \\
\hline Ogeng'o et al 2015 & Not reported & Not reported \\
\hline Present study & $1.41 \pm 0.56 \mathrm{~mm}$ & $1.42 \pm 0.53 \mathrm{~mm}$ \\
\hline
\end{tabular}

Table 7: Comparison of various studies on the length of the SCA

\begin{tabular}{|l|l|}
\hline Study & $\begin{array}{l}\text { Length of the SCA to its first } \\
\text { bifurcation }\end{array}$ \\
\hline Padmavathi 2014 & $6 \mathrm{~mm}$ to $23 \mathrm{~mm}$ \\
\hline Kalaiyalasi and Chitra 2018 & $9 \mathrm{~mm}$ to $24 \mathrm{~mm}$ \\
\hline Ogeng'o et al. 2015 & Not reported \\
\hline Present study & $3.77 \mathrm{~mm}$ to $33.53 \mathrm{~mm}$ \\
\hline
\end{tabular}

In conclusion, the study found that in the majority the SCA arose from the BA as a single trunk in $49.6 \%$. The most common anomaly was overall duplication of the SCA which observed at the rate of $35.5 \%$ while triplication of the SCA was seen in $4.9 \%$. In multiple SCAs, the diameter of the second SCAs reduced progressively but this was inconclusive in the case of a third SCAs. Nineteen were hypoplastic representing $16.8 \%$ of the SCAs while hundred and three (82.3\%) were normal. Agenesis and fenestration were not seen in the present study. The Knowledge on the anatomical variations of the SCA can improve diagnosis and management of posterior vascular occlusion and compression syndromes of cranial nerves III, IV and V.

\section{ACKNOWLEDGEMENT}

Special gratitude goes to Professor Krikor Erzingatsian and other faculty members; Dr Mutemwa, Dr Kafumukache, Mrs Siwale and my colleagues. This work would not have been possible without their support. I am indebted to them. 
Anatomy Journal of Africa. 2020. Vol 9 (1): 1789 - 1796.

\section{REFERENCES}

1. Avci E, Fossett D, Aslan M, et al. (2001). Surgical anatomy of the superior cerebellar artery. Turkey Neurosurgery. 11: 95-100.

2. Aydin M.E, Kaya A.H, Kopuz C, et al., (2011). Bilateral origin of superior cerebellar arteries from posterior cerebral arteries and clues to its embryological basis. Anatomy Cell Biology 44(2):1647.

3. Dagcinar, A. Kaya A.H. Aydin M.E et al. (2007). The superior cerebellar artery: anatomic study with review. Neurosurgery Quarterly 17(3):235-40.

4. Dodevski A, Lazarova D.T Zhivadinovik J. et al. (2015). Morphological Characteristic of the Superior Cerebellar Artery. Medical Sciences Journal XXXVI 1.

5. Gunnal S.A, Farooqui M.S, Wabale R.N (2014). Anatomical variations of the circulus arteriosus in cadaveric human brains. Hindawi Publishing Corporation Neurology Research International; Article ID 687281, 16. http://dx.doi. org/10.1155/2014/687281.

6. Habibi Z. Meybodi A.T, Maleki F. et al. (2011). Superior and Anterior Inferior Cerebellar Arteries and Their Relationship with Cerebello-pontine Angle Cranial Nerves Revisited in the Light of Cranial Cephalometric Indexes: A Cadaveric Study, Turkish Neurosurgery 2011, Vol: 21, No: 4, 504-515.

7. Kalaiyarasi S. and Chitra P.S (2018). A study of variations in the origin of superior cerebellar artery and the dimensions of its proximal segment. International Journal of Anatomy and Research 2018, Vol 6(1.1):4849-53.

8. Kalani M.Y, Hu Y.C, Spetzler R.F. (2013). A double-barrel superficial temporal artery-to-superior cerebellar artery (STA-SCA) and STA-to-posterior cerebral artery (STA-PCA) bypass for revascularisation of the basilar apex. Journal of Clinical Neuroscience 20:887-9.

9. Nagawa E, Okello M, Kiryowa H. et al. (2018). Terminal end Variations and Common Pathological Abnormalities of the Basilar Artery among the Ugandan Population: a Human Autopsy Study, Journal of Morphological Sciences 2018;35:110-115.

10. Ogeng'o J. Elbusaidy H. Sinkeet S. et al., (2015). Variant Origin of the Superior Cerebellar artery in a Kenyan black population, European Journal of Anatomy 19 (3): 287-290 (2015).

11. Padmavathi G. (2014). Study of the variations of superior cerebellar artery in human cadavers, International Journal of Research in Medical Sciences (2):699-703. www.msjonline.org

12. Nair P and Panikar D. (2015). Microsurgical management of aneurysms of the superior cerebellar artery-lessons learnt. Asian Journal of Neurosurgery Jan- Mar;10(1)47.

13. Standring, S. (2008). Gray's Anatomy; The Anatomical Basis of Clinical Practice, $40^{\text {th }}$ edition, Churchill Livingston Elsevier.

14. Zheng X.I, Feng B, Hong W, et al. (2012). Management of intra neural vessels during microvascular decompression surgery for trigeminal neuralgia. World Neurosurgery 77:771-4. 